\title{
Client acceptance decisions of Dutch auditing partners
}

\author{
Rafael Wittek $\cdot$ Theo van der Zee $\cdot$ Peter Mühlau
}

Published online: 29 February 2008

(C) The Author(s) 2008

\begin{abstract}
A vignette study of 567 client acceptance decisions by 67 Dutch auditors showed that the prospect of acquiring additional assignments significantly increases the likelihood that auditing partners accept an audit assignment from a new client, thereby violating a rule of the auditing profession. Audit firm strategy was found to moderate the effect of the acquisition of additional assignments: partners working in audit firms emphasizing a professional orientation are less likely to accept such risky assignments, whereas a commercial orientation of audit firms was found to exacerbate the effect of acquiring additional services. Contrary to expectations, punishment severity for professional mistakes increases the likelihood of client acceptance.
\end{abstract}

Keywords Client acceptance decision - Auditing · Firm strategy · Vignette study $\cdot$ Professional norms $\cdot$ Commercial orientation

\section{Introduction}

The recent financial scandals about fraudulent financial practices of multinationals such as ENRON, Parmalat, or AHOLD have caused much discussion about the

\footnotetext{
R. Wittek $(\bowtie)$

Department of Sociology/Graduate school ICS, University of Groningen, Grote Rozenstraat 31, 9712 TG Groningen, The Netherlands

e-mail: r.p.m.wittek@rug.nl

T. van der Zee

Korreweg 160-B, 9715 AK Groningen, The Netherlands

P. Mühlau

Department of Sociology, Trinity College Dublin, 3 College Green, Dublin 2, Republic of Ireland
} 
auditor profession. Some observers attribute the scandals to a failure of the auditing system. Auditors (or Chartered Accountants) may be too concerned with making profit, and might not take professional norms as seriously as they should. Professional norms are the rules, codes, and standards with which auditors should comply while exercising their profession. These are formulated by the International Federation of Accountants (IFAC) and, in The Netherlands, by the Dutch Institute for Chartered Accountants, NIVRA (2005). If an auditor fails to comply with the code of ethics for professional accountants (IFAC 2001), and the international standards on auditing (IFAC 2003), there will be an increased risk that a financial statement is materially misstated. For example, if an auditor does not spend the necessary amount of time and/or does not execute all the necessary tasks, the risk increases that mistakes in the financial statement are overlooked.

A violation of professional norms resulting in a misstated financial statement can have major consequences for both the individual auditor and the audit firm. Disciplinary law can prohibit the auditor to no longer function as an auditor. The audit firm can be held responsible for damage caused by the mistake, and in turn its reputation will be damaged. In sum, neglecting the codes and standards of the profession comes with considerable professional risks for individual auditors and auditing firms. In addition to the professional risks, professional misbehavior of auditors also bears societal risks. Auditing serves a public goal. Auditors who accept new clients despite an insufficient auditing budget and/or with the motive of acquiring additional assignments ultimately contribute to the erosion of trust and confidence in the auditing profession.

An increasing number of observers of the accountancy profession see a trend towards more rule violations and a decline in the independence commitment of auditors (Gendron et al. 2006). For example, since the passage of the U.S. Private Securities Litigation Reform Act in 1995, allegations of accounting fraud make up for an increasing percentage of litigation activity, in particular revenue recognition issues. From 1996 to 2006, 827 class action cases were settled for a total of $\$ 43$ billion, and these are only the cases including fraudulent inflation in the price of a corporation's common stock (Simmons and Ryan 2007). In 2006 alone, the total settlement reached an unprecedented $\$ 17.1$ billion ( $\$ 7.1$ billion of which are due to the Enron settlement alone). In over 55\% of the settlements in 2006, accounting issues were involved, and about 35\% involved a restatement of the financial statement (Simmons and Ryan 2007).

The erosion of professional norms due to increasing commercialization and profound changes in the reward and governance structures of auditing firms has been identified as one potential reason for this trend. With commercial motives becoming more prominent as a potential threat to professional ethics during all stages of an audit assignment, intra-organizational structures and mechanisms are likely to gain in importance as safeguards of professional behavior.

In this context, recent scholarship has drawn attention to the relatively neglected issue of client-acceptance decisions (Gendron 2002; Johnstone 2000; Johnstone and Bedard 2003). Due to continued fee pressure and litigation risk, issues related to the risks of doing business with new prospective clients have acquired an increasingly central position in the risk-containment efforts of auditing firms during the past 
decade (Johnstone 2000). One key problem during this early stage of the auditorclient relationship results from the fact that the prospect of acquiring additional services from a new client may lead audit partners to accept risky audit assignments. In The Netherlands, the independence regulations for accountants (NIVRA 2002, 2005) clearly specify that the accountant needs to be able to prove that the requested remuneration for the audit is not related to the expected delivery of other services (also referred to as the condition of independent price setting). Furthermore, the rules specify that the remuneration for an audit assignment needs to be high enough so that qualified personnel has enough time to carry out the assignment according to the rules specified by the profession (referred to as the audit budget sufficiency condition). In this context it should be noted that violations of the audit budget sufficiency and independent price setting conditions does not imply that the client is risky, i.e. they might occur with "problematic" and "average" clients alike.

Recent scholarship argues that organizational characteristics of auditing firms are likely to play a major role in the prevention and mitigation of such violations of professional rules during the acquisition phase. More specifically, Gendron (2002; see also Gendron et al. 2006) has developed a framework linking firm strategy with professional risk taking. Based on case study evidence from Canadian Big Five Accountancy firms, Gendron argues that a commercial vs. professional orientation of the accounting firm will moderate an audit partner's willingness to make a risky client acceptance decision. The key idea is that firms emphasizing a professional orientation, have strong sanction threats for professional misconduct, and apply skill rather than performance related compensation schemes, all of which will reduce the tendency to take risky client-acceptance decisions. In this article, we will put Gendron's model to a systematic test in the Dutch context. More specifically, we test the hypothesis that the opportunity to sell additional services to the client (e.g. the provision of tax advice, internal control and administrative organization) will increase the likelihood of risky client acceptance decisions more in audit firms with a commercial (as opposed to a professional) orientation. In order to test these claims, we conducted a questionnaire-based vignette study among audit partners in a sample of medium sized and large Dutch audit firms.

The article is organized as follows. In the next section, we elaborate the theoretical background and derive empirically testable hypotheses. In Sect. 3, we sketch the research design as well as the measures and statistical methods used. Section 4 presents the results. Section 5 discusses implications for future research and concludes.

\section{Theoretical background}

Several studies provide evidence that large scandals in the financial reporting of firms such as ENRON deteriorate the confidence in the independence and reliability not only of the involved auditing firms, but of the accounting profession as a whole, with the result of seriously hampering the working of financial markets (Eduardo et al. 2002; Lindberg and Beck 2004; Wielhouwer 2005). These findings show that the accounting profession, and consequently the working of financial markets, strongly relies on a collective reputation that cannot be reduced to the reputation of an individual audit firm. 
This collective reputation has attributes of a collective good (Olson 1965). All individual accountant firms benefit from investors' and other stakeholders' trust in the accountant function and the general reliability of financial statements. Likewise, damage of this collective reputation has adverse effects on the economic prospects of individual accountant firms and the stock market. The scandals also show the tension between individual and collective rationality associated with collective goods, since the costs of improper behavior such as reporting irregularities are not fully internalized by the firm causing the damage. Professions have developed and are legitimized by a system of norms and codes of behavior which safeguard its reputation against opportunism and incompetence. Compliance with these norms is achieved through professional socialization, and is enforced by sanctions (like threat of expulsion). However, even if the profession can allocate powerful sanctions, individual members may take advantage by violating professional norms if these offences are not perfectly observable. For many norms which regulate practices that may impede the independence of partners of auditing firms, such as low balling and the provision of non-audit services, offences are difficult to verify because the regulations leave room for interpretation, and depend on the judgment of the involved accountants (e.g. Van Schaik 2003). For example, although the Dutch regulations for accountants specify that auditing tasks require a sufficient budget, $65 \%$ of the Dutch public accountants claim that their budgets are not always sufficient for a proper audit (NIVRA 2004).

Given that the behavior of accountants is not fully determined by professional norms and sanctions, organizational structures and processes may be important determinants for behavior that potentially threatens auditor independence, such as the client-acceptance decision (Gendron et al. 2006). In this context, Gendron's (2002) elaboration of two logics of action is an important contribution for the understanding of the role of organizations in shaping auditor's client-acceptance decisions. Gendron (2002, p. 666) distinguishes between two "idealized, coherent and organized sets of values and ideas", one centered "on the notion of serving the public", the professional logic, and one centered on "the practitioner's financial self-interest", the commercial logic. Each of these logics reflect themselves in a distinctive set of organizational components pertaining to the firm's practice development strategy, system of management by objectives, partner compensation schemes and client-acceptance policies and corresponding attitudes of the participants. According to Gendron (2002), every accountancy firm has to reduce the tension between professional and commercial logics. This is achieved by making one of the two logics salient, with the other logic remaining in the background.

Gendron's model provides a useful framework for explaining client-acceptance decisions, since it points towards the intra-organizational tensions resulting from two competing sets of norms and values, and the resulting pressure on professional decision making of accountants. In what follows, we build on and refine Gendron's (2002) framework.

\subsection{Situational characteristics: the effect of additional services}

Carrying out an audit for a client usually provides an excellent opportunity for the auditor to discover in which areas the client could need additional advice (Gendron 
2002). In fact, audit firms very often provide additional services for their audit clients. For example, a survey of 307 large American companies revealed that firms paid their partners of auditing firms about two and a half times as much for additional services than they paid for the audit assignments (Tamminga 2001). Hence, the acquisition of an audit assignment can be an excellent strategy to increase the chances for obtaining profitable additional assignments for services in other areas not related to auditing (Gendron et al. 2006, p. 170). However, though obtaining additional services from an audit client can be very attractive from a commercial point of view, it can also put pressure on the professional norm of independence. For example, an audit partner can be tempted to change her professional judgment because she has a financial interest in providing additional services to the audit client. It can also happen that an auditor has to make a judgment about a financial statement drawn up by themselves.

We assume that additional services will never decrease the acceptance chance. If an audit partner is not interested in providing additional services to an audit client (e.g. because independence considerations outweigh expected benefits from additional services), she can choose to carry out only the audit assignment and simply reject the additional services. However, the greater the expected potential commercial benefits from additional services, the more likely they will at some point outweigh the expected negative consequences. The likelihood of accepting an audit assignment should therefore increase the more additional services the auditor thinks she will acquire from a new audit client:

Hypothesis 1 The more additional services that can be acquired from a potential new audit client, the more likely it is that an audit partner accepts a risky audit assignment.

\subsection{Firm strategy: commercial and professional orientation}

The "strategy" of an audit firm refers to the general policy audit firms develop to guide everyday practice of its members, such as client acceptance decisions. The strategy specifies the core values, principles, and priorities in order to manage the frequently conflicting demands partners of auditing firms have to face. We distinguish between two dimensions of strategy: the commercial, and the professional orientation.

Audit firms with a strong commercial orientation put a strong emphasis on financial results and continuously strive for improving their profitability. As Gendron noted, a strong commercial orientation is typically associated with attempts to diversify services, resulting in an integrated consultancy firm. The commercial orientation can go along with high levels of conformity with professional norms and investment in professional knowledge. However, conformity to professional norms is primarily motivated by the need to avoid liability claims and to maintain the firm's reputation. Investments in professional knowledge are driven by attempts to improve the firm's competitive position.

A strong professional orientation is centered on the collective good character of the reputation of audit services. Partners of auditing firms are instigated to give 
priority to norms such as auditor independence and professional expertise. Trust in the auditor profession and the public responsibilities of auditing are salient motives for the commitment to professional norms and cultivation of professional knowledge.

These different orientations have important implications for what is considered as an acceptable risk for accepting clients. Gendron (2002) remarks that in both types of firms, both logics need to be present to some extent. Commercially oriented firms cannot neglect professional norms, because obvious violations of the codes and rules will ultimately lead to reputation loss and litigation. Similarly, audit firms operating with a predominantly professional logic need to ensure their commercial viability in order to remain competitive. Hence, rather than conceiving auditing firms as following either a 'commercial' or a 'professional' logic, differences in orientation should be seen as a matter of relative salience of professional or commercial values in the culture and reward structure of the organization.

According to the commercial orientation, a risk is acceptable as long as the expected benefits of a cause of action exceed the expected costs. These firms may apply risk-management strategies as described by Johnstone (2000) to identify whether a client poses an undue risk.

Firms in which a professional orientation dominates do not differ from commercially oriented firms with regard to how they estimate the probability of the occurrence of mistakes and the potential benefits from assignments. However, they evaluate the potential costs of mistakes higher than audit firms with a commercial orientation. From a professional standpoint, the audit firm will also include the external effects of risk-taking in its calculation, such as the decreased confidence of society in auditors' judgments. Professionally seen, it is desirable to make decisions on the basis of a 'social costs/private returns analysis'. From this perspective, the threshold for accepting a client will be higher, as the perceived costs of a faulty audit weigh higher than for commercial firms. With regard to the professional orientation of an audit firm, we expect the following main effect on the client acceptance decision:

Hypothesis 2a The stronger the professional orientation within an audit firm, the lower the chance an audit partner accepts a risky audit assignment.

Professional orientation does not only increase the general tendency to reject clients as unacceptable risks. It will in particular temper the effect of additional services on client acceptance. This is less the case because the professionally oriented firm is disinterested in the revenue from additional services, but because it implies a violation of the independence norms of the auditing profession by confounding auditing tasks and the delivery of general financial services. Hence, we expect:

Hypothesis 2b The stronger the professional orientation within an audit firm, the less likely it is that the potential for offering additional services will increase the chance of accepting a risky audit assignment.

From a commercial point of view, we assume that the costs of risk-taking are estimated as lower in commercially oriented firms. It is important that all the hours 
spent can be charged. Gendron et al (2006), argue that the accountancy profession has undergone a shift from internalized professional standards to a conception of auditor independence as being largely conceived as a product of regulation (2006, p. 171). The introduction of non-audit services like management consulting shifted the reward structure "away from adherence to professional standards and ethics toward commercial gain" (2006, p. 170). Consequently, independence standards need to be safeguarded by 'a rigorous enforcement regime'. In firms in which such regimes are weak, a commercial logic is likely to dominate audit partner decision making. Flanked by the incentives resulting from performance related reward structures, the salient motivation in this logic will be the potential profit that might be realized with the new client. We therefore hypothesize that a more commercial orientation is likely to increase the likelihood of a risky client acceptance decision.

Hypothesis 3a The stronger the commercial orientation within an audit firm, the higher the chance an audit partner accepts a risky audit assignment.

The prospect of additional services will be more tempting for commercially oriented audit firms, because the increase in the transaction volume is not counterbalanced by a decrease in the price for the services. Consequently, we expect that a commercial orientation strengthens the effect of additional services on the likelihood of accepting a client:

Hypothesis $3 b$ The stronger the commercial orientation within an audit firm, the more likely it is that the potential for offering additional services will increase the chance of accepting a risky audit assignment.

\section{Methods}

The focus of the study is to understand how professionals make real decisions related to complex and sensitive issues. Client acceptance decisions are complex because of the multitude of factors that an auditor has to take into consideration, ranging from financial indicators like rentability of the client to internal control risks. Client acceptance decisions are sensitive because wrong decisions-apart from potentially resulting in the auditor being excluded from the profession-also are considered a matter of professional ethics. For example, an auditor who reports that he or she occasionally or systematically accepts new clients despite an insufficient audit budget would not only admit noncompliance to formal rules, but also declare to deliberately violate one of the core principles of the auditing profession. Professional decision making on complex and sensitive issues poses serious challenges to the research design of empirical studies (Griffin and Kacmar 1991; Taylor 2006). Conventional data collection techniques like document studies, observations, or retrospective interviews on past behavior soon face their limits due to severe social desirability pressures, post hoc rationalization, fading memory, or hindsight error (Taylor 2006, pp. 1188-1189). Several more recent contributions propose the use of factorial or vignette designs (Rossi and Nock 1982) for the study of complex and sensitive issues in professional decision making (Peabody et al. 2000; Taylor 2006). We therefore adopt a vignette design in our own study. 
In a vignette design, respondents are confronted with several case descriptions resembling real life decision situations. The descriptions differ on a limited number of theoretically relevant dimensions. The respondents are then asked to indicate how they would react if they encountered such a situation in their real work.

Several recent studies have argued that vignette or related designs yield superior results with regard to both external and internal validity (Griffin and Kacmar 1991; Peabody et al. 2000; Taylor 2006). Vignette designs are generally considered as unique in their capability to study the effect of multiple factors in complex decisions. For example, responses to judgment tasks in vignette experiments were found to closely resemble professional's real life judgments related to actual clients or patients (Taylor 2006, p. 1198). In the medical field, clinical vignettes were found to be a valid measure of the competence of physicians and the quality of their actual practice, in fact yielding more valid data than case records (Peabody et al. 2000). Vignettes also turned out to be a particularly useful and valid tool in the study of norm related behavior (Jasso 1988; Liebig and Mau 2002), and were proposed as a tool for the development of integrated risk management strategies to improve professional decision making (Taylor 2006, p. 1201).

Vignette designs need to meet several requirements in order to yield valid results. First of all, the case scenarios should be constructed from practice knowledge, resulting in true-to-life vignettes which resemble normal work situations (Taylor 2006). Similarly, the decision task should be framed as concretely and specific as possible, in order to closely approximate real-life decision-making questions (Alexander and Becker 1978). Finally, it is necessary to identify and approach appropriate respondents, e.g. professionals or practitioners who in fact have to deal with the question in their work practice.

\subsection{Data}

Data was collected by a survey of partners of Dutch audit companies. A two-stage, top-bottom sampling process was used: we first delineated companies that are likely to perform audit tasks, and then selected audit partners within the companies. The sample framework of the survey was larger companies included in the register of the largest association of chartered accountants in The Netherlands, the Dutch Institute of Chartered Accountants (NIVRA). The NIVRA is one of the two professional associations for accountants in The Netherlands. It has 13,000 members, compared to 6,500 members of the Dutch Order of Accountancy and Administration Consultants (NOVAA), the other association. NIVRA's chartered accountants have a higher education level (post academic) than administrative accountants of NOVAA, because the NIVRA diploma for chartered accountants is a post academic study, whereas the NOVAA diploma for administrative accountants is part of post higher vocational training. Though accountants associated with the NOVAA in theory are allowed to carry out the same accounting tasks as members of the NIVRA, in practice the large majority of members of NOVAA work as advisors and service providers (e.g. in the field of administration and taxes) for small and medium-sized enterprises, and do not carry out control or auditing tasks. Given that 
the majority of chartered accountants in The Netherlands are a member of the NIVRA, we restricted our sampling to this professional association.

We also selected companies with more than two audit partners or more than 25 employees, because smaller auditing firms organized in NIVRA are unlikely to perform auditing tasks. They traditionally serve companies in the small and medium-sized business sector (Veldhoen 1991), which are not obliged to carry out annual audits of their financial statements. In total, 868 organizations are listed on the NIVRA register. Exclusion of auditing firms with two or fewer audit partners or 25 or fewer employees yielded 117 firms that met our selection criteria. Of these, one audit partner was randomly selected. These partners were called and asked to participate in the survey. They were further asked to confirm that the company actually conducts audits, whether they in fact had the status of partner, whether they were actually involved in the auditing process, including acceptance decisions. 106 of them agreed to participate in the survey and received a written questionnaire. Finally, 67 audit partners of 67 audit firms sent back the questionnaire (response rate $67 / 117=57 \%$ ). All partners contacted were male.

\subsection{Research design}

In a vignette design, respondents were confronted with a scenario and asked to estimate the chance that the partners of their organization would accept a hypothetical audit task. The hypothetical decision situations were constructed in close cooperation with four experts, all of them practicing auditors. Based on their written and oral comments in various drafts, content and description of the vignettes was continuously improved to match a real-life decision situation as closely as possible. All four experts considered the final version as an accurate representation of a potential real-life client-acceptance decision.

The scenario describes a new 'average' client operating in an industry sectorchosen by the respondent-with whom the respondent is familiar. Internal control risks, inherent risk, as well as the financial indicators of rentability, solvency and liquidity were described as 'average' for the sector. The audit assignment covered 3 years.

The remaining elements of the hypothetical audit assignment followed a $3 \times 3$ factorial design. The first factor was related to the size of the auditfees that could be charged. The second factor was related to the size of additional services that could be provided to the audit client if the audit task is accepted. All respondents were confronted with the full set of all nine possible combinations, yielding $603(67 * 9)$ possible observations, 573 of which contained valid responses.

In the remainder of the questionnaire, respondents were asked to indicate the importance of various incentive systems, the strength of punishment for mistakes, and the strength of the professional or commercial orientation in the firm. As there were substantial correlations among all items inquiring the importance of compensation criteria, these items were normalized before they were aggregated to the three different factors. 


\subsection{Dependent variable}

The acceptance of a client was measured as the perceived chance (in percentages) that the audit task as described in the vignette would be accepted within the audit firm. This indirect assessment was chosen because direct confrontation of an auditor with a violation of norms or professional rules (as implied by some of the scenarios) may evoke defensive or socially desirable responses. As the description of the client and the task was quite general, and the response refers to the typical behavior in the firm, asking respondents to estimate chances rather than provide a discrete decision alternative appeared to be more appropriate.

\subsection{Independent variables}

The size of the additional services consisted of three conditions. The first condition reflected the situation that there was no chance to provide the client with additional services. In the remaining two conditions, the audit company could reckon on additional services for EUR 14,000 or EUR 28,000, respectively. As preliminary analyses showed, the relationships between the numerical values of the factors and the dependent variable are linear. Therefore, we used both the size of the additional services and the size of the audit fee as continuous variables in the analysis. This transformation does not affect the results.

Firm Strategy was measured by a set of items addressing the importance of strategic goals. In contrast to the expectation of a bi-polar continuum, factor analysis revealed two orthogonal components. "Firm strategy" thus consists of two distinctive dimensions, the commercial and the professional orientation. Commercial orientation of the firm was measured by five items. Respondents were asked to indicate to what degree the following beliefs were considered to be important inside the firm $(0=$ not important at all, $3=$ very important). The first two items addressed the perceived importance of the financial result and of profitability. The third item inquired how important it is to be seen as a consultant by clients. According to Gendron (2002), commercially orientated audit firms want to be seen as consultants by their audit clients because they want to acquire additional (consultancy) services. Finally, two further items are related to the importance of avoiding liability claims and reputation damage. The resulting scale has a moderate but acceptable reliability $(\alpha=.57)$.

Professional orientation of the firm was measured with the same five-item format as it was used to assess commercial orientation. The items addressed the importance of (a) being considered as independent and having professional expertise, (b) two key norms of the auditor profession, (c) professional codes of behavior, (d) providing accurate and trustworthy information to clients and (e) of behaving in line with the public interest in the accounting function. These five items yield a scale with a reasonable reliability $(\alpha=.74, n=67)$.

\subsection{Interaction effect of additional services and independent variables}

It has been argued that the impact of the perceived opportunity to offer additional services to the client is contingent on the firm's strategy and material incentives 
provided by the firm. In order to test these interaction effects, we computed (twoway) interaction variables by multiplying the variable additional services with these independent variables. The parameter estimates of these interaction effects indicate to what degree the impact of additional services on the assignment acceptance decision increases or decreases with high or low values on the independent variables (e.g. commercial or professional orientation, punishment).

The (two-way) interaction variables are likely to have an effect only in a situation where the audit budget is insufficient. However, in order to assess this impact, threeway interactions with the variable audit budget sufficiency would need to be added to the model. The low sample size of our study does not allow for the testing of three-way interactions without running the risk of producing a highly over-specified model. We therefore did not add three-way interactions. The parameter estimates of the two-way interactions therefore represent the effects under the conditions of sufficient and insufficient audit budgets.

\subsection{Control variables}

A straightforward indicator of the risk involved in a client acceptance decision is the degree of audit budget sufficiency. Audit fees are usually based on the number of hours that are needed to complete a task, multiplied by the hourly rate that the audit firm charges for a given assignment. An audit budget is said to be sufficient if the client can be charged for all hours necessary to complete the assignment according to professional standards. If the audit budget is sufficient, audit firms will usually accept the clients as long as there are no exceptional commercial and professional risks associated with the assignment. An audit budget is insufficient if the time that would be necessary to carry out the assignment in compliance with professional norms exceeds the chargeable time and the audit firm is familiar with the branch of trade of the client. Insufficient audit budgets decrease the likelihood of accepting the assignment for two reasons. First, when less than the professionally required time is used to carry out the task, the risk that the auditor commits a professional mistake increases. Second, even if all the professionally necessary time is spent on the assignment, an audit partner acts against professional norms which require that an auditor must be able to prove that the time charged is sufficient to perform the task in compliance with professional norms (IFAC 2001). In both cases, the audit partner runs a (personal) risk (e.g. punishment by disciplinary law). We therefore expect a positive relationship between audit budget sufficiency and the likelihood of accepting an audit assignment. Variations in audit budget sufficiency were measured by systematically varying the size of the audit fees in the vignettes. Three conditions were distinguished. In the first condition, the audit fee reflects the full cost-plus value of the audit task (100\% sufficiency; 25,000 Euro). The remaining two conditions reflect different degrees of audit budget insufficiency 90\% (22,500 Euro), and $80 \%$ (20,000 Euro), respectively. We assume that the likelihood of acceptance will be unity under the $100 \%$ sufficiency condition, whereas the $80 \%$ condition reflects the situation with the highest risk in our study.

Material incentives, rewards, and punishments are known to play an important role in affecting decision making and behavior in audit firms (Burrows and Black 
1998; Hackenbrack and Nelson 1996; Libby and Lipe 1992; Trompeter 1994). For example, the more an audit partner's reward is based on the number of acquired assignments (acquisition payment), the higher the compensation the audit partner receives when he or she acquires an assignment, thereby increasing the chance of accepting a risky audit assignment. Extra audit assignments or additional services give audit partners the opportunity to charge for more hours. Similarly, if payment is based on efficiency criteria, to achieve high efficiency, an audit partner must charge for as many of the total available hours as possible. Given the large variety of incentive schemes that can be found in auditing firms, we included several variables to control for the impact of compensation related factors. Compensation schemes were measured by a set of items where the respondents evaluated the importance of different types of compensation rules for their own compensation. The four response categories ranged from "absolutely not important" to "very important".

First, acquisition based rewards were measured by the importance of the number of audit jobs and the number of additional services. Both items were normalized and combined $(\alpha=.90, n=67)$.

Second, efficiency based rewards (Mudrick 1990) are based on the number of hours charged ('billings') in proportion to the number of hours that partners of auditing firms and their subordinates spend on assignments ('billable hours'). Efficiency-based rewards were measured by four items addressing the importance of the number of productive and declared hours of the respondent, and the number of productive and declared hours of the respondent's subordinates. The normalized and combined items yielded a reliable scale $(\alpha=.90, n=65)$.

Third, unit profit sharing was measured with one item addressing the relative importance of the financial result of the organizational unit the respondent is accountable for his compensation.

Fourth, experience-based rewards were measured with one item addressing how important experience in the field of accountancy is for his compensation. An audit partner's reward usually contains a fixed part, the size of which is contingent upon their experience. Experience-based rewards preclude the possibility to influence one's salary by taking professional risks. Since risk-taking in this case would only imply that an audit partner puts future rewards at stake, experienced-based rewards are likely to function as an incentive to prevent professional risk-taking.

Fifth, the larger the reward differences resulting from differences in performance, the more audit partners will try to perform as best as they can in order to receive a high reward (Lazear 1998), and will be more inclined to take risks (Becker and Huselid 1992). Since relative performance is what counts in such tournament based reward systems, we use compensation inequality as an indicator for the presence of a tournament reward system. It was measured by asking the respondent to estimate the difference, in percent, between the earnings of the highest and the lowest earning partner within the firm $(1=0-15 \%, 5=>200 \%)$.

Finally, we consider the effect of punishment for misstated financial statements. Audit firms that wish to avoid damage to finances and reputation due to noncompliance to professional norms will try to prevent audit partners from taking professional risks by threatening to punish their mistakes. The stronger the punishment, i.e. the larger the costs for the auditor, the less the auditor is inclined to 
take professional risks. Three items on negative sanctions were used to measure the punishment of professional misbehavior: negative effects for careers within company, dismissal from the firm, loss of accreditation as auditor. Respondents were asked whether or not each of the three sanctions was present in the firm. The three items form a 'perfect' Mokken or Guttman scale (Sijtsema and Molenaar 2002): $\mathrm{H}$ value of all the items $=1.00, \mathrm{H}$ value of the scale $=1.00$, number of Guttman errors $=0$. This implies that there is perfect consensus among the respondents with regard to the relative severity of each of the three types of sanctions, with negative consequences for the career representing the weakest form of punishment and expulsion from the profession the most severe one.

The variables measuring material incentives and punishment are only weakly related to the dimensions representing the strategy of the firm (see Table 1). Material incentives are thus not strongly aligned with the firm's strategy.

Organizational size (measured by the number of employees) and productivity (measured as relative capacity utilization in the form of productive use of personnel) were added as control variables. The size of the organization may be related to the risk-bearing capacity of the organization; moreover, the larger auditing organizations may be more dependent on their general reputation and less dependent on particular business ties. The degree of capacity utilization obviously has a potential influence on the willingness to accept under-financed jobs and the keenness to acquire additional services.

Tables 1 and 2 report descriptions of and zero-order correlations among these variables.

\subsection{Method of analysis}

The data have a nested structure where situations (vignettes) are nested in respondents. The appropriate statistical models in this case are multi-level models (also called hierarchical linear models) which use several random components (error terms) in order to ensure that the observations can be treated as independent and take into account that there are respondent-specific effects (Snijders and Bosker 1999).

A robustness check was carried out, because the dependent variables (the estimated chance of accepting the task) are limited to the range of $0-100 \%$, bimodally distributed and skewed to the right $(100 \%)$, the individual-level residuals are not normally distributed. We examined whether this violation of distribution assumptions affected the results by estimating an ordinal regression with deciles as dependent variables. The results proved to be robust, as significance levels as well as the size of the effects remained largely unchanged and lead to the same qualitative conclusions.

\section{Results}

We suggested that professional risk-taking of partners of auditing firms would be affected by the opportunity to acquire additional assignments and the degree to 


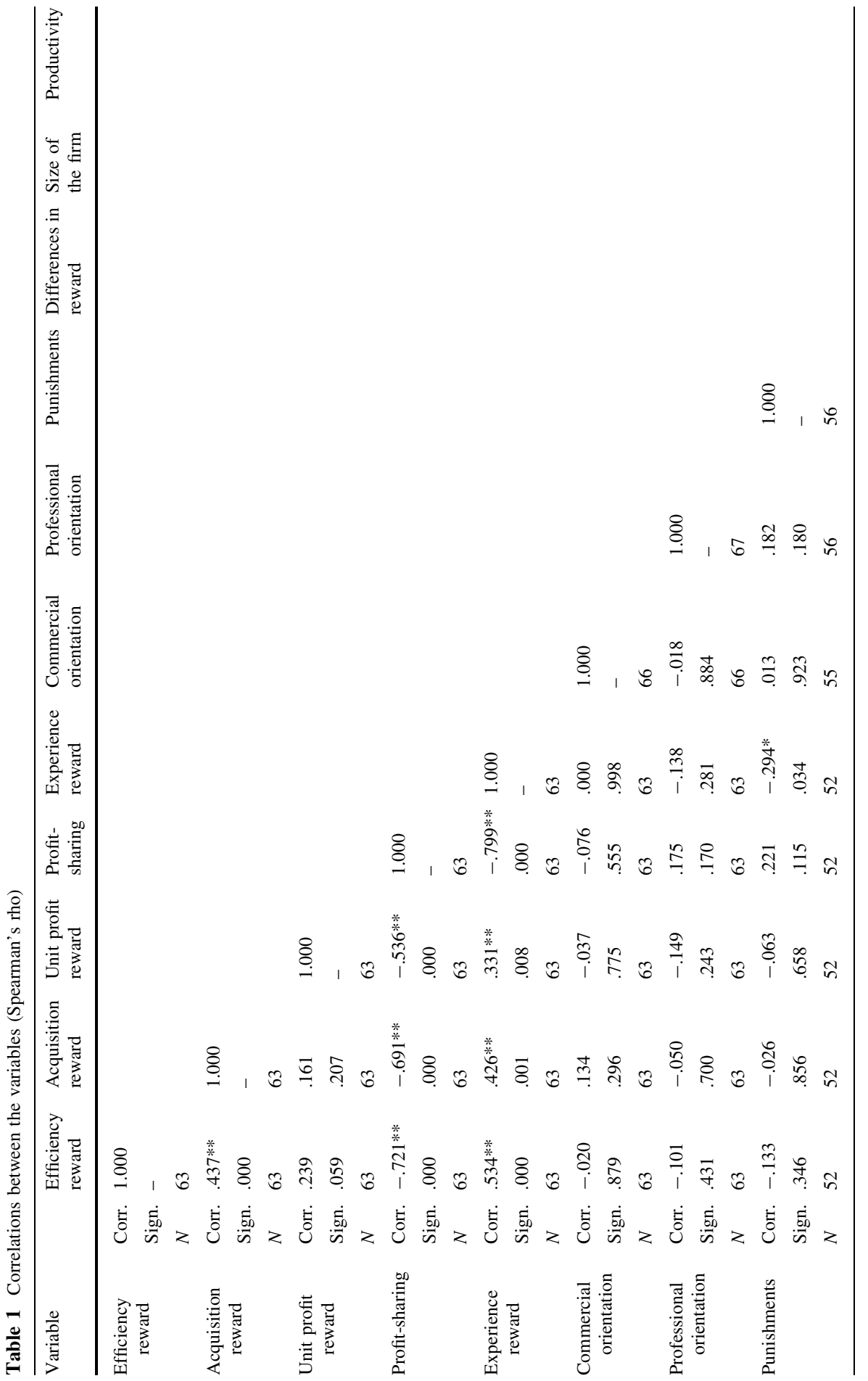

\section{를 Springer}




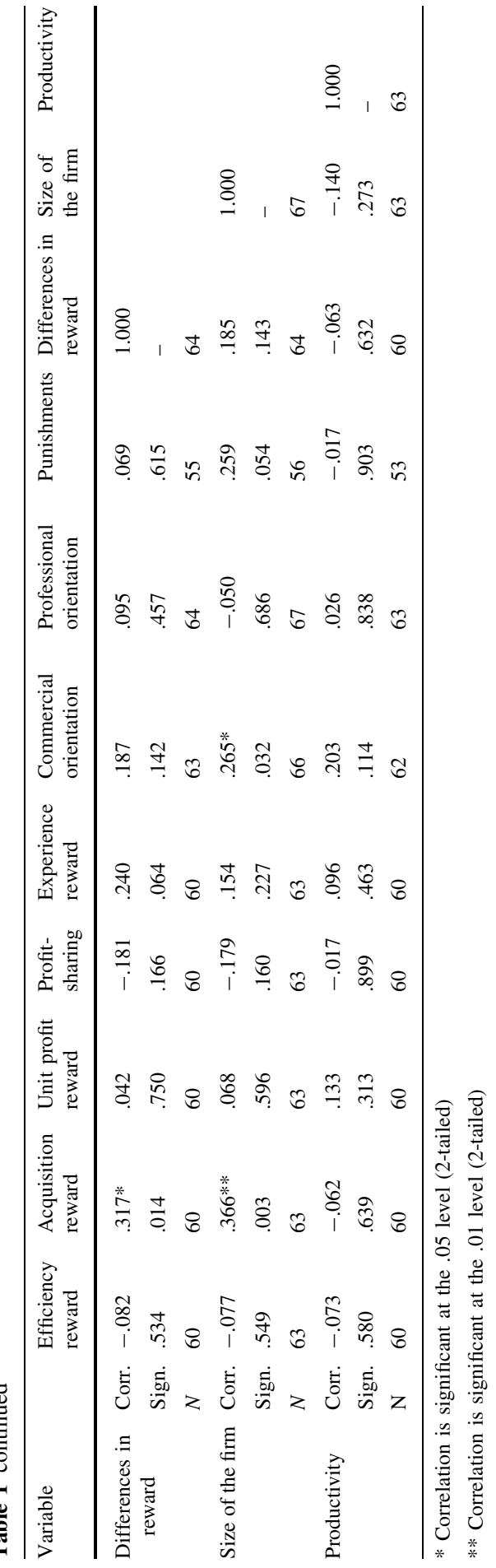


Table 2 Descriptive statistics

\begin{tabular}{|c|c|c|c|c|c|c|c|}
\hline Variable & $\begin{array}{l}\text { Lowest } \\
\text { possible score/ } \\
\text { measured } \\
\text { score }\end{array}$ & $\begin{array}{l}\text { Highest } \\
\text { possible/ } \\
\text { measured } \\
\text { score }\end{array}$ & $\begin{array}{l}\text { Lowest } \\
\text { measured } \\
\text { standardized } \\
\text { score }\end{array}$ & $\begin{array}{l}\text { Highest } \\
\text { measured } \\
\text { standardized } \\
\text { score }\end{array}$ & $\begin{array}{l}\text { Mean } \\
\text { score }\end{array}$ & SD & $\begin{array}{l}\text { Frequency } \\
\text { of missing } \\
\text { values }\end{array}$ \\
\hline $\begin{array}{l}\text { Efficiency } \\
\text { reward }\end{array}$ & $0 / 0$ & $12 / 12$ & .00 & 2.50 & .72 & .56 & 4 \\
\hline $\begin{array}{l}\text { Acquisition } \\
\text { reward }\end{array}$ & $0 / 0$ & $6 / 4$ & .00 & 1.15 & .28 & .36 & 4 \\
\hline $\begin{array}{l}\text { Unit profit } \\
\text { reward }\end{array}$ & $0 / 0$ & $3 / 3$ & .00 & 2.50 & .79 & .65 & 4 \\
\hline $\begin{array}{l}\text { Profit } \\
\text { sharing }\end{array}$ & $0 / 0$ & $3 / 3$ & .00 & 5.00 & 2.54 & 1.58 & 4 \\
\hline $\begin{array}{l}\text { Experience } \\
\text { reward }\end{array}$ & $0 / 0$ & $3 / 3$ & .00 & 2.11 & .67 & .63 & 4 \\
\hline Punishments & $0 / 0$ & $3 / 3$ & - & - & 1.71 & .82 & 11 \\
\hline $\begin{array}{l}\text { Commercial } \\
\text { orientation }\end{array}$ & $0 / 6$ & $15 / 15$ & - & - & 11.11 & 2.00 & 1 \\
\hline $\begin{array}{l}\text { Professional } \\
\text { orientation }\end{array}$ & $0 / 6$ & $15 / 15$ & - & - & 13.03 & 1.96 & 0 \\
\hline $\begin{array}{l}\text { Differences } \\
\text { in reward }\end{array}$ & $1 / 1$ & $5 / 5$ & - & - & 1.37 & .90 & 3 \\
\hline $\begin{array}{l}\text { Size of the } \\
\text { firm }\end{array}$ & $1 / 1$ & $6 / 6$ & - & - & 3.28 & 1.24 & 0 \\
\hline Productivity & $1 / 2$ & $5 / 4$ & - & - & 3.27 & .63 & 4 \\
\hline
\end{tabular}

which firm strategy emphasizes compliance to professional norms vs. the realization of commercial profits. Further, we predicted that a highly commercial firm strategy will exacerbate the positive effect of additional service acquisition on client acceptance, whereas a professional orientation will temper this effect. The results of our data analyses confirm the majority of these claims.

Three models were estimated. They are summarized in Table 3.

Model 1 contains only the co-variates at situation level. In model 2, the strategy and incentive related variables as well as the control variables have been added. The weak correlation between strategy and incentive measures implies that the effects of firm strategy are not mediated by the incentive structure. Hence, the organizationlevel predictor variables can be entered simultaneously into the regression, without loss of information. Also included in this model is a vector of interaction effects between the dummy for a sufficient budget for the audit job and the explanatory variables (not reported). Model 3 extends model 2 by a vector of interaction effects between the explanatory variables and the value of the additional services the organization can sell to the client.

As can be seen from Table 3, the relationship between the value of additional services and the chance of accepting an audit job is positive and highly significant, thereby supporting $\mathrm{H} 1$. The strongly significant negative coefficient for the professional orientation is also in line with our expectations, thereby supporting 
Table 3 Results of multilevel-analysis of the effect of situational and organizational characteristics on the likelihood of accepting an audit assignment

\begin{tabular}{|c|c|c|c|c|c|c|}
\hline \multirow[t]{2}{*}{ Fixed effects } & \multicolumn{2}{|l|}{ Model 1} & \multicolumn{2}{|l|}{ Model 2} & \multicolumn{2}{|l|}{ Model 3} \\
\hline & Coefficient & SE & Coefficient & SE & Coefficient & SE \\
\hline Intercept & $85.62 \#$ & 5.66 & 85.82\# & 5.98 & $85.75 \#$ & 5.98 \\
\hline \multicolumn{7}{|l|}{ Situational characteristics } \\
\hline Audit budget & $306.45^{* * *}$ & 29.66 & $306.53 * * *$ & 29.57 & $306.13 * * *$ & 29.58 \\
\hline Additional services & $18.45 * * *$ & 1.92 & $18.46^{* * *}$ & 1.91 & $18.29 * * *$ & 1.82 \\
\hline \multicolumn{7}{|l|}{ Firm strategy } \\
\hline Commercial orientation & - & - & -.77 & 1.54 & -.76 & 1.54 \\
\hline Professional orientation & - & - & $-6.65 * * *$ & 1.44 & $-6.64 * * *$ & 1.44 \\
\hline \multicolumn{7}{|l|}{ Firm strategy $\times$ additional services } \\
\hline Com. orientation $\times$ add. serv. & - & - & - & - & $1.46 * * *$ & .48 \\
\hline $\begin{array}{l}\text { Prof. orientation } \times \text { add. serv. } \\
\text { Control variables }\end{array}$ & - & - & - & - & $-1.07 * *$ & .46 \\
\hline Size of the firm & - & - & 3.72 & 2.72 & 3.72 & 2.72 \\
\hline Productivity & - & - & -5.89 & 4.82 & -5.88 & 4.82 \\
\hline Efficiency reward & - & - & $17.39 * * *$ & 6.56 & $17.35 * * *$ & 6.56 \\
\hline Efficiency reward $\times$ add. serv. & - & - & - & - & -1.10 & 2.07 \\
\hline Acquisition reward & - & - & $15.13^{*}$ & 9.94 & $15.11^{*}$ & 9.95 \\
\hline Acquisition reward $\times$ add. serv. & - & - & - & - & 1.73 & 3.14 \\
\hline Experience reward & - & - & $-8.28 *$ & 5.98 & $-8.30^{*}$ & 5.99 \\
\hline Experience reward $\times$ add. serv. & - & - & - & - & -.06 & 1.84 \\
\hline Reward differences & - & - & $14.31 * * *$ & 4.20 & $14.29 * * *$ & 4.20 \\
\hline Reward difference $\times$ add. serv. & - & - & - & - & -.10 & 1.37 \\
\hline Unit profit reward & - & - & -.46 & 4.80 & -.39 & 4.80 \\
\hline Punishments & - & - & $-7.37 * *$ & 3.99 & $-7.37 * *$ & 3.99 \\
\hline Punishments $\times$ add. serv. & - & - & - & - & $2.99 \ddagger$ & 1.23 \\
\hline$-2 \log$ likelihood & 4667.90 & & 4606.99 & & 4588.67 & \\
\hline$R^{2}$ 'between organizations' ${ }^{\text {'a }}$ & - & & $43 \%$ & & $43 \%$ & \\
\hline$R^{2}$ 'within organizations' & $44 \%$ & & $64 \%$ & & $64 \%$ & \\
\hline
\end{tabular}

$* p<.10$ (one-sided); ** $p<.05$ (one-sided); *** $p<.01$ (one-sided); $\ddagger p<.05$ (two-sided); $\#<<.01$ (two-sided)

${ }^{a}$ Explained variance is computed according to the method suggested by Snijders and Bosker (1999). Model 1 does not have explained variance 'between organizations', because it contains only variables on the level of the situation. Variables on the lowest level cannot explain variation on the highest level

H2a: the stronger the professional orientation of an audit firm, the less likely the acceptance of a risky assignment becomes. As predicted in $\mathrm{H} 2 \mathrm{~b}$, the professional orientation of the firm also tempers the effect of the potential acquisition of assignments on the likelihood of accepting a risky assignment: the interaction effect between professional orientation and additional services is positive and significant.

No support is found for H3a: the main effect of a commercial orientation of the firm on acceptance of risky assignments is not significant. However, in line with 
$\mathrm{H} 3 \mathrm{~b}$, a commercial orientation exacerbates the effect of the prospect of additional services on client acceptance: the interaction effect is significant and positive. In sum, four of our five hypotheses are supported by the data.

Of the control variables, organizational size and productivity do not have a significant effect on the client acceptance decision. As expected, efficiency rewards, acquisition rewards, and reward differences in the firm increase the likelihood of accepting a risky assignment. Experience based rewards decrease this risk, but this effect is not significant. The expected discouraging effect of strong sanctions of professional misconduct is confirmed by a significantly negative relationship between punishment severity and the chance of accepting an audit job. None of the interaction effects between rewards and additional services is significant, indicating that reward systems as such do not moderate the effect of additional services on client acceptance. However, rather than decreasing the impact of additional services on risk-taking behavior, punishment severity actually reinforces this effect, as the positive interaction effect shows: the stronger the punishment for professional mistakes in a firm, the more likely it is that the prospect of acquiring additional services encourages an auditor to accept an audit assignment. We will discuss this unexpected interaction effect in the following section.

\section{Discussion and conclusion}

By simultaneously investigating the role of organizational and situational determinants of risk-taking, our study integrates the findings of recent earlier research on client-acceptance decisions. On the one hand, Johnstone (2000), and Johnstone and Bedard (2003) provide a careful analysis of the different dimensions of risk related to the acceptance of a client, but devote little attention to aspects of organizational governance. On the other hand, Gendron's (2002) field study at three Big Six firms located in Canada provides an insightful analysis of the important role of professional and commercial organizational cultures, but does not statistically test hypotheses. Our empirical results can be seen as a statistical test and further refinement of Gendron's (2002) hypotheses. To the best of our knowledge, we have conducted the first quantitative study of client-acceptance decisions in a Dutch context, previous literature being restricted to Anglo-American firms. Although we found no patterns that would contradict earlier findings in the Anglo-American context, the usual caution should be applied with regard to potential generalizations of the findings to other countries.

Our results show that the opportunity of generating additional assignments does indeed provide strong incentives for an audit partner to accept an audit assignment, which, from a professional point of view, would better be rejected. As predicted, a professional orientation not only decreases risk taking, but significantly tempers the incentive effect resulting from the prospect of generating additional services. We also found that a firm's commercial orientation as such does not affect the client acceptance decision. However, the temptation to accept a risky client if it potentially yields additional assignments turns out to be stronger for audit partners in firms with a commercial strategy than for partners in firms with a strong professional strategy. 
These findings warrant the conclusion that firm strategy-i.e. to what degree professional or commercial goals are emphasized-matters for professional risk taking. Hence, our study lends support to earlier suggestions (Gendron 2002) that the dominant logic of action in an audit firm should be considered as a serious factor leading to rule violations.

In this context, one of our empirical findings related to the control variables needs some more attention: punishment severity exacerbates the impact of additional services on risk taking, rather than tempering it. One possible explanation of this unexpected relationship might be that auditing firms which encourage an aggressive 'client acquisition culture' also threaten to severely punish misconduct of partners. These sanctions should contain the risk inherent in this marketing strategy and counter the temptation for the partners. If this is the case, the positive relationship between punishment severity and the propensity to accept new clients indicates reverse causality, since it is the acquisition culture which drives the adoption of strict sanctions, rather than vice versa.

Another explanation for the unexpected effect of punishment severity on client acceptance might be that accountancy firms which allocate strong sanctions for professional misconduct are also those which have institutionalized other preventive measures contributing to the prevention of professional mistakes. One way of achieving this objective is to strictly separate activities of auditing and other forms of assignments for the same client ('Chinese Walls'). The two activities are then carried out by different subdivisions of the organization. Such a setup increases the independence of the auditor carrying out the audit assignment, and decreases the risks inherent in simultaneously carrying out auditing and consultancy assignments for the same client. If this reasoning is correct, the presence of Chinese Walls should increase the impact of the potential to acquire additional services on the likelihood of accepting an audit assignment. If the strong punishment of professional misconduct indeed correlates highly with the presence of 'Chinese Walls', it would thereby explain the positive effect of punishment on risk-taking. To what degree this assumption holds would be a fruitful question for future empirical research.

A third interpretation relates to the incentive effects emanating from different punishment regimes. In a formal model, Narayanan (1994) has shown that under a proportionate liability regime (in which auditors pay only for their share of the damage), auditors have a stronger incentive to minimize litigation costs by working harder than under joint and several liability regimes (in which they pay there own damages plus those of insolvent codefendants). Audit quality is likely to increase under proportionality regimes. ${ }^{1}$ In The Netherlands, an unlimited liability regime applies, and most stakeholders in the accountancy profession advocate a switch towards a proportionate liability system or one of its variants (Directorate General for Internal Market and Services 2007). Our finding that firm level variations in punishment severity significantly affect risk behavior shows that between-firm variations in punishment regimes deserve some closer scrutiny. Our measurement of punishment severity combined three variables (negative effects for careers within company, dismissal from the firm, loss of accreditation as auditor). In the light of

\footnotetext{
$\overline{1}$ We are indebted to an anonymous reviewer for bringing this interpretation to our attention.
} 
Narayanan's (1994) analysis, future research might use a more refined measure of firm level punishment regimes, disentangling the different kinds of incentive effects they might exert on individual auditors.

This brings us to the possible limitations of our study. One of the most common criticisms against the use of experimental methods in general and vignette designs in particular is their assumed limited external validity (Lucas 2003). Vignettedesigns would have the disadvantage that they refer to hypothetical situations and would therefore not be able to capture actual behavior in real life situations. In other words, vignettes represent artificial designs which do not adequately represent the "real world". As a result, participants in such designs would behave differently than they would in real life. As mentioned above, the encouraging findings of several validation studies contradict this claim. True-to-life vignettes have a high degree of external validity. This holds in particular if they are-as in our study-based on indepth practitioner knowledge and submitted to a population of professionals who are frequently confronted with similar situations. Some studies even found them to be superior to other methods in this respect (Peabody et al. 2000). Hence, though vignette designs manipulate situations by making theoretically relevant conditions salient and eliminating others, this does not imply that participants experience the conditions as less real. And since "no methodological procedures in and of themselves will allow for generalization across settings" (Lucas 2003, p. 245), vignette research designs as such are no less suited to study professional decision making than other methodologies. With the test of a theoretical relationship being among the primary objectives of our study, we found the vignette design to be particularly useful for the study of multiple antecedents of risky client-acceptance decisions. Given the promising findings of other studies of professional decision making applying this method, future research of this topic is likely to benefit from making more use of this underutilized research design.

With regard to the specific vignettes used in our study, one other issue should be noted. Many respondents indicated a $100 \%$ likelihood for acceptance of an audit even if the audit budget was insufficient. This means that the scenarios presented to the respondents might have been positively biased. This bias may be the cause of the non-significant result of the interactions between the different types of material rewards and additional services. It should also be noted that the audit assignments described in the vignettes were comparatively small. Assessing to what degree our findings could be generalized to situations with large assignments (e.g. for big multinational firms) would be an interesting task for future research.

While we found only a weak relationship between firm strategy and organizational incentive structures, we also found that both firm strategy and incentive structure had consistent effects on the propensity to accept new clients. One implication of this pattern is that the Dutch auditors in our study apparently experience conflicting signals from the organization (e.g. material rewards providing strong incentives for client acquisition, whereas the firm strategy emphasizes compliance to professional norms). Even auditing firms with a strong professional orientation may operate with performance related incentives. A policy aiming to prevent violation of professional norms by strengthening the professional 
commitment of partners of auditing firms will remain ineffective unless it also tackles organizational incentive structures.

In the auditing profession, professional risk-taking can come in many guises. In our study, we focused on client-acceptance decisions, which take place at the early stages of the whole auditing and accounting process. Consequently, our model probably does not provide much insight into the determinants of risk-taking in later stages of the auditing process. Nevertheless, in many cases a large number of the problems as they may occur at later stages in the auditing process might possibly be traced back to an erroneous or risky acceptance decision. Many audit firms have recognized this, and consequently started to invest into risk-containment programs. Our guess would be that the success of these efforts will depend on the material incentives provided for the partners of auditing firms as much as on the firm strategy and the resulting organizational culture.

Acknowledgments Financial support by The Netherlands' Organization for Scientific Research (NWO) to Rafael Wittek (grants number 016.005.052 and 400-05-704) is gratefully acknowledged.

Open Access This article is distributed under the terms of the Creative Commons Attribution Noncommercial License which permits any noncommercial use, distribution, and reproduction in any medium, provided the original author(s) and source are credited.

\section{References}

Alexander, C. S., \& Becker, H. J. (1978). Use of vignettes in survey-research. Public Opinion Quarterly, 42(1), 93-104.

Becker, B. E., \& Huselid, M. A. (1992). The incentive effects of tournament compensation systems. Administrative Science Quarterly, 37(2), 336-350.

Burrows, G., \& Black, C. (1998). Profit-sharing in Australian big 6 accounting firms: An exploratory study. Accounting, Organizations and Society, 23, 517-530.

Directorate General for Internal Market and Services. (2007). Consultation on auditors' liability. Summary report. http://ec.europa.eu/internal_market/auditing/docs/liability/summary_report_en.pdf.

Eduardo, M., Zhang, T., \& Moore, B. C. (2002). The effect of the Enron collapse on investor perceptions of auditor independence and financial statement reliability. Working Paper, University of Mississippi.

Gendron, Y. (2002). On the role of the organization in auditors' client-acceptance decisions. Accounting, Organizations and Society, 27, 659-684.

Gendron, Y., Suddaby, R., \& Lam, H. (2006). An examination of the ethical commitment of professional accountants to auditor independence. Journal of Business Ethics, 64, 169-193.

Griffin, R., \& Kacmar, K. M. (1991). Laboratory research in management - misconceptions and missed opportunities. Journal of Organizational Behavior, 12(4), 301-311.

Hackenbrack, K., \& Nelson, M. W. (1996). Auditor's incentives and their application of financial auditing standards. The Accounting Review, 71(1), 43-59.

IFAC. (2001). Code of ethics for professional accountants. International Federation of Accountants.

IFAC. (2003). Objective and general principles governing an audit of financial statements. International Federation of Accountants.

Jasso, G. (1988). Whom shall we welcome - elite judgments of the criteria for the selection of immigrants. American Sociological Review, 53(6), 919-932.

Johnstone, K. (2000). Client-acceptance decisions: Simultaneous effects of client business risk, audit risk, auditor business risk, and risk adaptation. Auditing, 19, 1-25.

Johnstone, K., \& Bedard, J. (2003). Risk management in client-acceptance decisions. Accounting Review, 78, 1003-1025. 
Lazear, E. P. (1998). Personnel economics for managers. New York: Wiley.

Libby, R., \& Lipe, M. G. (1992). Incentives, effort, and the cognitive processes involved in accountingrelated judgments. Journal of Accounting Research, 30(2), 249-273.

Liebig, S., \& Mau, S. (2002). Einstellungen zur sozialen Mindestsicherung. Ein Vorschlag zur differenzierten Erfassung normativer Urteile. Kölner Zeitschrift fur Soziologie und Sozialpsychologie, 54(1), 109-134.

Lindberg, D. L., \& Beck, F. D. (2004). Before and after Enron - CPAs' views on auditor independence. CPA Journal, November, 36-39.

Lucas, J. W. (2003). Theory-testing, generalization, and the problem of external validity. Sociological Theory, 21(3), 236-253.

Mudrick, H. L. (1990). Partner compensation. The CPA Journal Online. http://www.nysscpa.org/ cpajournal.

Narayanan, V. G. (1994). An analysis of auditor liability rules. Journal of Accounting Research, 32(Supplement), 39-59.

NIVRA. (2002). RA-gids 2002/2003. Amsterdam: Koninklijk Instituut van Registeraccountants (Royal Institute for Registered Accountants).

NIVRA. (2004). Trends in accountancy. Amsterdam: Nederlands Instituut voor Registeraccountants.

NIVRA. (2005). Nadere voorschriften inzake onafhankelijkheid van de accountant. Amsterdam: Nederlands Instituut voor Registeraccountants en Nederlandse Orde van Accountantadministratieconsulenten.

Olson, M. (1965). Logic of collective action: Public goods and the theory of groups. Boston, MA: Harvard University Press.

Peabody, J. W., et al. (2000). Comparison of vignettes, standardized patients, and chart abstraction - a prospective validation study of 3 methods for measuring quality. Jama-Journal of the American Medical Association, 283(13), 1715-1722.

Rossi, P. H., \& Nock, S. L. (Eds.). (1982). Measuring social judgments: The factorial survey approach. Beverly Hills, CA: Sage.

Sijtsema, K., \& Molenaar, I. W. (2002). Introduction to non-parametric item response theory. Thousand Oaks: Sage.

Simmons, L., \& Ryan, E. (2007). Securities class action settlements: 2006 Review and analysis. Boston: Cornerstone Research. http://securities.stanford.edu/.

Snijders, T. A. B., \& Bosker, R. (1999). An introduction to basic and advanced multilevel modeling. London: Sage.

Tamminga, M. (2001). Openheid over belangenconflicten onder accountants. NRC Handelsblad, April 27.

Taylor, B. J. (2006). Factorial surveys: Using vignettes to study professional judgement. British Journal of Social Work, 36(7), 1187-1207.

Trompeter, G. (1994). The effect of compensation schemes and generally accepted accounting principles on audit partner judgment. Auditing, 13(2), 56-68.

Van Schaik, F. (2003). Een toereikende vergoeding voor de jaarrekeningscontrole. Maandblad voor Accountancy en Bedrijfseconomie, juni, 254-260.

Veldhoen, M. (1991). Een goed imago is het halve werk - internationalisering van de Nederlandse accountantsbranche. Unpublished Master's thesis. Utrecht: Instituut voor Ruimtelijke Organisatie TNO/Rijksuniversiteit Utrecht.

Wielhouwer, J. L. (2005). The cost of broken trust. Stock price reactions to financial reporting irregularities. Working Paper. Tilburg University.

\section{Author Biographies}

Rafael Wittek is professor of sociology and chair of the Department of Sociology, University of Groningen, The Netherlands, and Scientific Director of the Interuniversity Center for Social Science Theory and Methodology (ICS). He received his PhD in Sociology from the University of Groningen. His research interests are in the fields of organizational governance and change, social network analysis, and sociological theory. 
Theo van der Zee holds a B.A. degree in Financial Management and a M.A. degree in Sociology from the University of Groningen. He works at the Noordelijke Rekenkamer (Northern Audit Office), The Netherlands.

Peter Mühlau received his $\mathrm{PhD}$ in Sociology from the University of Groningen. He is lecturer at the Department of Sociology, Trinity College Dublin (Ireland). His current research interests are in the field of labor markets, organizations, and migration. 